\title{
An Experimental Study of the Effect of Computer Assisted Learning on Metacognitive Performance Development in Psychology Teaching
}

\author{
Ahmet Coymak \\ Columbia University, United States
}

\begin{abstract}
There is a growing interest in the use of computer-based learning environments to enhance learning in higher education, but the implications of this on the improvement of metacognition in higher education have yet to be adequately explored. In the current study, 175 students who enrolled in an introductory psychology course were randomly assigned to experimental and control groups (computer-assisted vs. self-managed). In the computer-assisted condition, besides the lecture delivered four hours per week and for three months in total, students took a set of assignments based on evidence-based teaching in a computer-based environment. The control group, however, took these assignments as in-and-out class activities without using a computer environment. An assessment based on Bloom's taxonomy was utilized to obtain metacognitive and competency scores for both groups. The results of the study showed that the students who completed the structured learning assignments as computer-based, self-learning environment showed better metacognition performance than those in the self-managed group, who did not engage with the online platform, even though there was no significant difference between the groups regarding competence on the course's learning objectives. The current experiment offers an empirical validation for why instructors should use technology as a self-regulatory tool that enhances students' metacognitive performance and competence of learning outcomes.
\end{abstract}

Keywords: Metacognition; University teaching; Self-regulation in learning; Computerbased learning; Pedagogical tools, Higher education

\section{Introduction}

"In our culture, psychology is the most prominent category through which we understand ourselves as human beings."

Elizabeth Dreyer, 2005

Suggestion for the usage of technology to help students to develop metacognition and selfregulated learning habits is one thing in common among diverse pedagogical thoughts (e.g., Azevedo, 2005a; McLoughlin \& Lee, 2007). Although there is rapid integration of technology in a favorable policy environment, little is known about the ways in which structured online educational materials help students to enhance their metacognitive performance, which basically refers to knowledge about knowledge or the extent to which one separates what they know and do not (Azevedo, 2005b; Ertmer, 2005; Flavell, 1979). Parallel to this rapid enthusiasm 
about the use of technology in education; there has been a growing interest in the use of computer-based learning environments to enhance psychology learning in higher education (HE). However, the implications of this have yet to be adequately explored. Therefore, this study aims to explain the role of structured independent learning assignments (ILAs) such as online computer based environment, on developing metacognitive skills among students in psychology education.

Today, what we broadly understand by psychology is that it is the scientific study of thought, emotions, and behaviors. It is essential for students in higher education (HE) to have the ability and awareness to differentiate "common sense" and research evidence in the 21st-century complex modern world, in which successful business and social life require engaging knowledgeintensive business life and constant learning. Based on scientific research in psychology, understanding the reasons behind some fundamental questions such as why we think in a particular way, what we do, and how we do can help university students adjusting to this new world and be extremely helpful to students' future careers as well as their academic achievement no matter what students' major course of study may be. Although a strong emphasis is placed on separating research evidence and common sense in the field of psychology, most psychology instructors perform contrary to what they teach to students. On this, Groccia and Buskist (2011) stated that "within the higher education institutions...the choice of teaching strategies is based largely on experiential, common sense, or anecdotal evidence" (p. 6) and the field of psychology is not an exception.

Providing an intellectually-stimulating learning environment for HE students successfully depends on how the courses are structured by instructors, yet evidence shows that the current trend in regular curricula and assessment has extinguished students' enthusiasm, motivation and creative thinking (Robinson, 2009). Besides, little achievement has been accomplished to improve critical thinking and complex reasoning for students in HE while these skill sets have been seen as an essential part of higher education (Arum \& Roska, 2011, p.35). The recent developments in educational psychology such as evidence-based teaching (EBT) offer many possibilities to overcome the obstacles that higher education face today because of being accustomed to traditional lecturing and curricula (Dunn, Saville, Baker, \& Marek, 2013; Groccia \& Buskist, 2011).

Although EBT was developed first in the practice of medicine, it has rapidly spread as a pedagogical technique to improve the effectiveness of teaching practices in the classroom (Davies, 1999). There are a number of methods and diverse approaches for instructors to apply EBT, such as testing effect, spaced learning, metacognitive development, writing to learn, and interactive teaching (for the details, see Dunn et al.). However, there are some skeptical views on the technique (Biesta, 2007), while there has been a growing interest in EBT to provide more efficient, evidence-based, open and democratic educational practices in HE (Azevedo, 2002; Davies, 1999; Mitchell, 2014; Stuart, Tondora, \& Hoge 2004). Certainly, one of the most important skills that students should develop through $\mathrm{HE}$ is metacognition, which can basically be defined as knowledge about what they already know or do not know (Flavell, 1979). Metacognition, therefore, can help us to change our thoughts by critically thinking what we already know, which is fundamentally necessary for creative thinking (Brinol \& DeMarree, 2012; Feldhusen, 1995). Therefore, I expected in this study that the computer-aided self-regulatory tools such as the structured independent learning assignments would have a positive impact on the development of metacognition in psychology education. 
Many researchers show that the usage of technology which is closely linked to self-regulated learning tools helps to improve individuals' metacognitive skill (e.g., Ball \& Stacey, 2005; Meyer, Abrami, Wade, Aslan, \& Deault, 2010; Quintana, Zhang, \& Krajcik, 2005). For instance, Hwang, Chen, Shadiev, and Li (2011) experiment on 32 junior high school students showed that students who use a virtual pen (VPEN) to review and annotate their own text showed the significantly higher score on learning achievement in math compared to the text reviewed by their peers. Therefore, they suggested that students are benefited from actively reviewing own text by facilitation of VPEN to improve their metacognitive performance. Similarly, Psycharis, Botsari, Mantas, and Loukeris (2014) showed that using computational experiment methodology, simulated by computer helps primary school students to improve their content relevant metacognitive strategies. Tatar, Akpinar, and Feyzioglu's (2013) case study on elementary school students also suggests that computer-aided learning affect students' emotional attribution to science subjects and also facilitate their metacognitive skills such as self-monitoring, selfchecking, and self-assessment.

Although all of these studies conclude that technology usage in learning process facilitates to improvement of students' metacognitive skills, they did neither use computer-aided learning as independent variable or experimental condition in their research nor measure metacognitive performance to see whether the effect of improvement in metacognitive skills caused by computer mediation in learning process. The current study, therefore, fills the gap to provide empirical evidence whether there a causal relationship between the improvement of metacognitive performance and technology usage in the learning process.

\section{Method}

\section{Sample}

Participants were 175 introductory psychology students in the 2013-2014 academic term at the Izmir University of Economics where the medium of instruction is English. There were 114 females and 61 males in the study, and their mean age was $19.83(S D=1.85)$. All students' families have a relatively similar background, are in the upper middle class and are fairly well educated.

\section{Procedure}

All of the undergraduate students in the university were free to choose one of the four sections of 6 ECTS $^{1}$ Introduction to Psychology course on a first-come, first-served basis. The course was both an elective to all students in the university and a compulsory departmental. Although it was a mandatory course for freshmen psychology students ( $42 \%$ of participants), they were also free to choose the sections in which they wished to enroll ( $37 \%$ of in experimental conditions). The course was designed to achieve the objectives based on the recommendations of the American Psychological Association (APA) on undergraduate students' competencies (Board of Educational Affairs, 2013). Therefore, the design of the course has covered the goal of APA

\footnotetext{
${ }^{1}$ ECTS is a consortium on European Credit Transfer and Accumulation system (for detail, European Union Bologna Process, http://ec.europa.eu/education/ects/ects_en.htm)
} 
student competencies; knowledge base in psychology, scientific inquiry and critical thinking, ethical and social responsibility in a diverse world, communication, and personal development. All students were informed at the beginning of the academic term that instead of providing a straightforward classical lecture format, the course was designed to cover main theories of the psychology by encouraging participants to involve discussions, demonstrations, and some small applications in and out of the class time. Two sections were randomly assigned to the computerassisted condition ( $N=75$ ) while the other two were assigned to a self-managed group ( $N=100$ ). All independent learning assignments (two assignments for each of the nine chapters) and inclass activities that were structured by the experimenter followed the EBT techniques (Dunn, Saville, Baker, \& Marek, 2013) provided by the course book (Feeldman, 2013). To encourage student involvement in these self-regulating learning sessions, 15 per cent of the course grade was given to the assignment and activities for both groups.

In the computer-assisted condition, besides the instruction in class the lecture delivered four hours per week and for three months in total, students took the set of ILAs in a computer-based environment that covered interactive book reading, evaluation of concept clips, practical tests, and short essay writing. The group used an ebook and followed all of the ILAs via an online system supplied by McGraw-Hill Connect, while the self-managed group took these independent learning assignments in a classical, in and out-class activities without using the online system. Both groups were asked in the exams how much time they spent on the out of class assignments and no significant difference was found between the groups $[F(1,174)=2.11, p>.05]$.

\section{Random Assignment and Experimental Challenges in Natural Educational Settings}

Students were self-assigned into the experiment and control group although they were invited the classes randomly. Therefore, the reason of student chose to particular groups was not controlled by the experimenter. Thus, there may lead the experiment some unforeseen sampling biases. However, to provide valid sampling with the randomization of the error variance across groups, there are several precautions implemented, and some possible cofounding of self-selection procedure were controlled.

One of the possible sampling biases might be a number of students from the same major would have chosen in disproportionally either experimental condition and control condition. Therefore, before analyzing the treatment effect on metacognition and learning competence, the distribution of students' major in the university was controlled. There were no significant differences between the experimental group and control group in terms of the proportion of each students' major to choose the Introductory to Psychology class. Furthermore, the class was compulsory to psychology students, the large number of psychology students were taken place in either experimental and control condition. Fortunately, the proportion of psychology students across the groups was reasonable. However, in any case, students' major and psychology major students could have had a confounding effect on the study dependent variables. Therefore, MANCOVA analysis was chosen to examine two related dependent variables in the same model with a covariate of students' major (Tabachnick \& Fidell, 2007) Because of the expected high correlation between metacognition and competence on course outcomes (Azevedo, 2002), composite dependent variables should also be examined. 
The second possible sampling bias might occur because some students took the class morning and others afternoon. Therefore, among the four classes, the experimental group was chosen from one morning class and one afternoon class while the other pair of classes with the same combination was chosen as the control condition. Finally, it was hard to claim that ILAs were performed equally by an online software and instructor for both groups. Therefore, to avoid misleading and possible systematic error in natural educational settings, and increase the internal validity of the study, the reader must be cautious that there was an obstacle of unseen unequal application of ILAs. However, as a precaution of this self-assignment and unequal application of ILAs in natural educational context, the final precaution was to reduce the expected effect size and to increase the error probability by calculating estimated sample size. Power analysis for a MANCOVA with two levels and two dependent variables was conducted in G-POWER 3.1 to determine a sufficient sample size using an alpha of 0.01 , a power of 0.90 , and a small effect size $(f 2=0.06)$. The desired sample size of the calculation was 170 which would meet the total number of students enrolled in the class.

\section{Measures}

\section{Competencies in Learning Outcomes}

Student competency in the course's learning outcomes was measured by adopting the Bloom's (1956) taxonomy which represents the hierarchy of skills development on expected outcomes such as knowledge, comprehension and application. To measure the skills at different levels of cognitive complexity and higher-order skills, which particularly require more sophisticated cognitive processes (Crowe, Dirks, \& Wenderoth, 2008; Nevid \& McClelland, 2013), competency on course learning outcomes was measured by a series of multiple-choice exams, grouped according to Bloom's taxonomy (memory, understanding, and apply) to be able to develop a reliable and valid assessment (Haladyna, 1999). Each group on Bloom's taxonomy had eleven questions; and each memory items on learning outcomes was scored as two points, understanding items were awarded three points, and apply items were awarded four points. There were also four extra questions to measure the perceived time that they spend to assignments and course evaluation. These questions were awarded 16 points. Therefore, the minimum possible score was 16 points while the maximum possible score was 115 . Three multiple-choice exams were administered during the academic term. Following, each student's competency was scored by aggregating the items across the three exams, and no penalty was applied for students' incorrect answers. Sample questions for each hierarchical level are provided in Supplementary Material 1.

\section{Level of Metacognition}

One of the techniques in common to measure students' metacognitive monitoring is the confidence rating (Couchman et al., 2016). Therefore, following each exam item, students were asked to evaluate how much they know whether their answer is correct or not on a 4-point Likert-type scale ( $1=1$ know it, $2=$ think so, $3=$ not sure, $4=$ no idea) to measure student's metacognitive knowledge. Metacognitive performance, which is the accuracy between metacognitive knowledge and proficiency in the competence of learning objectives, therefore, was measured based on the algorithm as follows: 
If the student gave a correct answer to the exam question and following this indicated a 1 ( 1 know it), their metacognition score for the question was four, and it sequentially decreased towards one depending on how confident they were in their answer. If the student gave an incorrect answer to the exam question and indicated four (no idea), their metacognition score was four, and it sequentially decreased towards one depending on how confident they were on the correctness of their answer. All individual scores were summed to produce a total metacognition score for each of the three exams separately. For each participant, a final composite variable for the metacognitive performance was created by taking the mean value of the metacognition scores of the exams. The higher scores show the higher level of metacognitive performance on the students' proficiency in the competence of learning objectives.

\section{Analyses and Results}

A between-subjects multivariate analysis of covariance (MANCOVA) was performed on two dependent variables (competence and metacognition), and adjustment was made for students' major (covariate). The independent variable was learning environment (online vs. traditional). SPSS 23 General Linear Model (GLM) software was used to perform the analyses. Violation of the assumptions for MANCOVA was checked, and normality, homogeneity of variance covariance-matrices, linearity, and multicollinearity were found to be satisfactory. The total $\mathrm{N}=$ 175 was reduced to 168 due to deletion of 7 participants for missing scores on metacognition.

Wilks' criterion showed that the linear composite of metacognition and competence were not related to the covariates (students' major), $[\mathrm{F}(2,164)=.998, \mathrm{p}=.88, \eta 2=.002]$. To examine more specifically, the power of the covariate to adjust dependent variables, multiple regression analyses were performed for both metacognition and competence. The students' majors also could not provide adjustment to both metacognition and competence; therefore, no further mean adjustment for students' major was found to be necessary. However, the composite dependent variables were significantly affected by the learning environment $[F(2,164)=11.093$, $p<.001, \eta 2=.12]$.

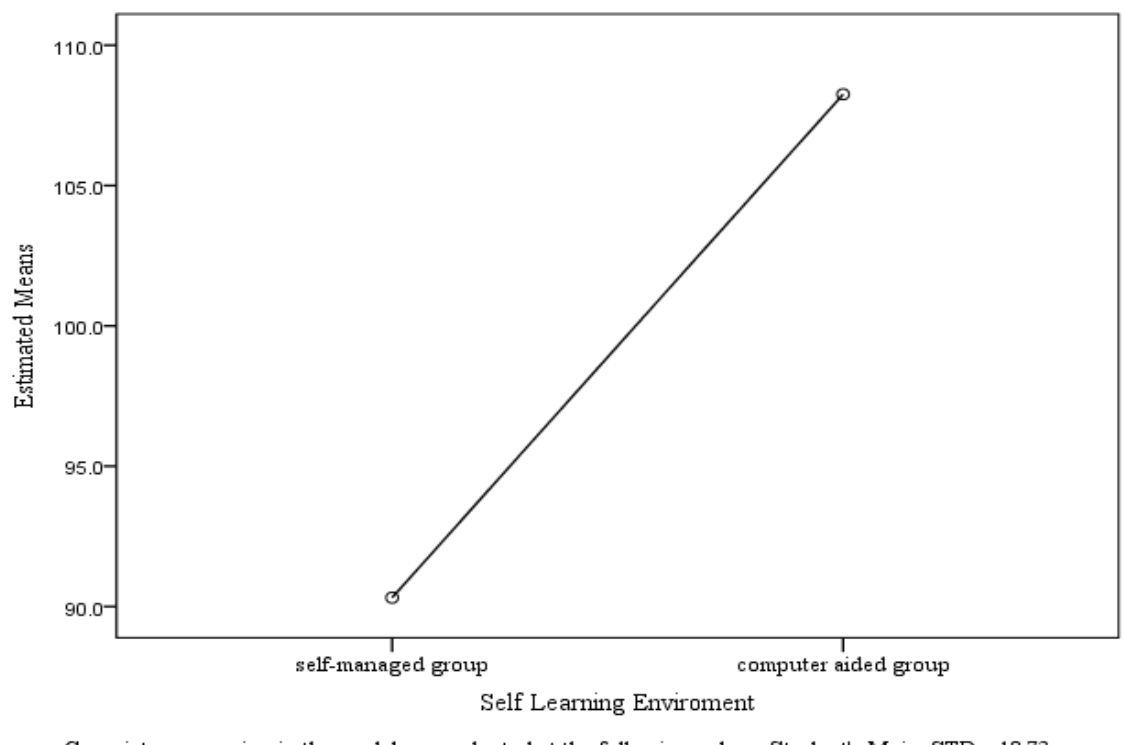

Covariates appearing in the model are evaluated at the following values: Student's Major STD $=18.73$

Figure 1. Means of Metacognition for both Traditional and Online Self-Learning Environments 
To examine the impact of each main effect on metacognition and competence, univariate and Roy-Bergman step-down analyses in which metacognition was given the priority was performed. Metacognition made a significant contribution to the composite of the dependent variables that best distinguish between online and traditional self-learning environment, stepdown $[F(1,165)$ $=4.54, p=.035, \eta 2=.027]$. In other words, metacognition was the most influenced dependent variables in the model by the self-learning environment. As seen in the main effects in Figure 1, the results revealed that students who studied independent learning assignments in the computer-based environment showed higher metacognitive performance $(M=108.608, S D=$ 45.67) than those who had the independent learning assignments in a traditional way ( $M=$ $94.21, \mathrm{SD}=41.75)$. Both a univariate comparison and stepdown analysis did not reveal any difference between the learning environments on the competence of students' learning outcomes. Table 1 shows both univariate and stepdown analyses.

Table 1. Test of Students' Majors and Learning Environment

\begin{tabular}{|c|c|c|c|c|c|}
\hline Effect & DV & Univariate $\mathrm{F}$ & df & StepdownF & $\alpha$ \\
\hline \multicolumn{6}{|c|}{ Covariate } \\
\hline & Metacognition & .21 & 1 & .21 & .001 \\
\hline & Competence & .25 & 1 & .04 & .002 \\
\hline \multicolumn{6}{|c|}{$\begin{array}{l}\text { Learning } \\
\text { Environment }\end{array}$} \\
\hline & Metacognition & $4.542 * *$ & 1 & $4.542^{* *}$ & .027 \\
\hline & Competence & .897 & 1 & 2.39 & .005 \\
\hline
\end{tabular}

$* * \mathrm{p}<.01$

\section{Discussion}

The aim of this experiment was to understand whether the structured ILAs in a computer-based environment positively affected student metacognition in psychology education. In order to extend knowledge about the relationship between students' metacognitive skills, the competence on course learning outcomes and ILAs, the role of the self-learning environment in psychology education was considered. The results partially supported the initial hypotheses generated from pedagogical approaches and metacognition literature. The findings of the present study clearly show that computer-based self-learning environments predict students' better metacognition performance. The present findings seem to be consistent with other research which has found a positive association between metacognition and self-regulated learning in HE (for a detailed review, see Azevedo \& Hadwin, 2005).

However, what is surprising is that no differences were found in self-learning environment (computer aided or not) on students' competence on learning outcomes in the experiment. In other words, students who took the structured self-learning assignments have the same level of competencies on learning outcomes regardless of the learning environments. A possible explanation for this surprising finding might be that EBT has already provided a remedy for the success of learning objectives for both instructors and students (Mitchell, 2014; Stuart, Tondora, \& Hoge 2004). It is, therefore, likely that such connections exist between learning achievement and well-structured independent learning assignments, provided by the course instructor, prepared in line with the guidance of EBT (see the guidance for EBT: Dunn, Saville, Baker, \& 
Marek, 2013). However, more experimental research on this topic needs to be undertaken before associations among EBT, self-regulated learning, metacognition, and self-learning environment are more clearly understood.

In future investigations, it might be possible that EBT is used as an experimental manipulation of learning achievement. However, a laboratory setting instead of using a real class for this experiment would be more convenient in this experiment since not only it is easier to control possible confounding effects, but also the instructor may be ethically concerned about using enhanced learning tools for a group of students in their course as I was before the present study was designed.

One of the challenges today which an instructor faces in HE is to apply new techniques (e.g., EBT) in psychology education, which require more time and concentration than a traditional technique. However, not only may EBT provide a better achievement of student's self-regulated learning and achievement competence in course learning outcomes, but it also helps an instructor to prepare transparent and fair grading system on performance test for a psychology class. It may also provide interchangeable feedback between students and instructors to achieve learning objectives of the course in line with suggestions of APA (2013), which aimed to advance the quality of psychology courses in an international context. This view may also have positive impact on students' metacognition, by which they can evaluate their own class performance instead of increasing the perception that the grade is given by a lecturer, which is well known as one of the most difficult challenges for lecturers in university education for practical training and skill development of students (Ustunluoglu \& Gungor-Culha, 2012).

Adopting the new technology to the course (e.g., interactive e-book, books' online platforms) helps reduce the amount of time required for application of these new pedagogical techniques, and provides useful data for the instructor to analyze student competence, obstacles, and metacognition to achieve course objectives by providing a rich learning environment (Ozcelik \& Acarturk, 2011; Poirier \& Feldman 2007; Shepperd, Grace, \& Koch 2008). The results of the present study also suggest that structured independent learning assignments in a computer environment helps to increase students' metacognition performance even though the performance of these assignments regardless of the learning environment may not differentiate student competence on the course's learning objectives. The present experiment offers an empirical validation for why psychology instructors should use technology as a self-regulatory tool that enhances student metacognition skills, which are one of the fundamental necessities in creative thinking that students need for their future success in the complex 21st-century world (Brinol \& DeMarree, 2012; Feldhusen, 1995).

\section{Practitioner Notes Based on the Arguments and Results}

- Computer-assisted self-learning environments help students to build better metacognition performance.

- Achieving learning outcomes (obtaining high grade on the exam), however, may not directly relate to metacognitive development.

- Evidence-Based Teaching (see Dunn, Saville, Baker, \& Marek, 2013 for the guidance for EBT) techniques are effective tools for the success of learning objectives for both instructors and students 
CONTEMPORARY EDUCATIONAL TECHNOLOGY, 2019, 10(1), 94-105

DOI: https://doi.org/10.30935/cet.512539 - TYPE: Research Article

- Adopting the new computer technologies to a course (e.g., interactive e-book, books' online platforms) helps to reduce the amount of time required for application of these new pedagogical techniques, and provides useful data for the instructor to analyze student competence, obstacles, and metacognition to achieve course objectives by providing a rich learning environment

\section{Acknowledgement}

The authors would like to thank Dr. Emma O'Dwyer and Dr. Mehmet Akif Guzel for their contributions to an earlier version of the manuscript.

\section{Funding}

This project has not received any funding to declare. However, the author thanks to both Suleyman Demirel University and Izmir University of Economics for their support. 


\section{References}

Azevedo, R. (2002). Beyond intelligent tutoring systems: Computers as metacognitive tools to enhance learning? Instructional Science, 30, 31-45.

Azevedo, R. (2005a). Computer environments as metacognitive tools for enhancing learning. Educational Psychologist, 40(4), 193-197. doi:10.1207/s15326985ep4004

Azevedo, R. (2005b). Using hypermedia as a metacognitive tool for enhancing student learning? The role of self-regulated learning. Educational Psychologist, 40, 199-209.

Azevedo, R. \& Hadwin, A. F. (2005). Scaffolding self-regulated learning and metacognitionImplications for the design of computer-based scaffolds. Instructional Science, 33(5), 367-379.

Ball, L. \& Stacey, K. (2005). Teaching strategies for developing judicious technology use. Technology-Supported Mathematics Learning Environments (2005 National Council of Teachers of Mathematics Yearbook, pp. 3-15). Reston, VA: NCTM.

Biesta, G. (2007). Why 'what works' won't work: Evidence-based practice and the democratic deficit in educational research. Educational Theory, 57, 1-22.

Brinol, P. \& DeMarree, K. G. (2012). Social metacognition. New York: Psychology Press.

Crowe, A., Dirks, C., \& Wenderoth, M. P. (2008). Biology in bloom: Implementing Bloom's taxonomy to enhance student learning in biology. CBE-Life Sciences Education, 7, 368381. http://dx.doi.org/10.1187/cbe.08-05-0024

Davies, P. (1999). What is evidence-based education? British Journal of Educational Studies, 47(2), 108-121.

Dunn, D. S., Saville, B. K., Baker, S. C., \& Marek, P. (2013). Evidence-based teaching: Tools and techniques that promote learning in the psychology classroom. Australian Journal of Psychology, 65(1), 5-13. doi:10.1111/ajpy.12004

Ertmer, P. A. (2005). Teacher pedagogical beliefs: The final frontier in our quest for technology integration? Educational Technology Research and Development, 53(4), 25-39.

Feldhusen, J. F. (1995). Creativity: A knowledge base, metacognitive skills, and personality factors. The Journal of Creative Behavior, 29(4), 255-268.

Flavell, J. H. (1979). Metacognition and cognitive monitoring: A new area of cognitivedevelopmental inquiry. American Psychologist, 34(10), 906.

Groccia, J. E. \& Buskist, W. (2011). Need for evidence-based teaching. New Directions for Teaching and Learning, 2011(128), 5-11.

Haladyna, T. M. (1999). Developing and validating multiple-choice test items. Mahwah, NJ: Lawrence Erlbaum Associates

Hwang, W. Y., Chen, N. S., Shadiev, R., \& Li, J. S. (2011). Effects of reviewing annotations and homework solutions on math learning achievement. British Journal of Educational Technology, 42(6), 1016-1028. http://doi.org/10.1111/j.1467-8535.2010.01126.x

McLoughlin, C. \& Lee, M. J. (2007, December). Social software and participatory learning: Pedagogical choices with technology affordances in the Web 2.0 era. In ICT: Providing choices for learners and learning. Proceedings ASCILITE Singapore 2007 (pp. 664-675). 
Meyer, E., Abrami, P. C., Wade, C. A., Aslan, O., \& Deault, L. (2010). Improving literacy and metacognition with electronic portfolios: Teaching and learning with ePEARL. Computers \& Education, 55(1), 84-91.

Mitchell, D. (2014). What really works in special and inclusive education: Using evidence-based teaching strategies? London: Routledge.

Nevid, J. S. \& McClelland, N. (2013). Using action verbs as learning outcomes: applying Bloom's taxonomy in measuring instructional objectives in introductory psychology. Journal of Education and Training Studies, 1(2), 19-24.

Ozcelik, E. \& Acarturk, C. (2011). Reducing the spatial distance between printed and online information sources by means of mobile technology enhances learning: Using 2D barcodes. Computers \& Education, 57(3), 2077-2085.

Poirier, C. R. \& Feldman, R. S. (2007). Promoting active learning using individual response technology in large introductory psychology classes. Teaching of Psychology, 34(3), 194196.

Psycharis, S., Botsari, E., Mantas, P., \& Loukeris, D. (2014). The impact of the computational inquiry based experiment on metacognitive experiences, modelling indicators and learning performance. Computers and Education, 72, 90-99. http://doi.org/10.1016/ j.compedu.2013.10.001

Quintana, C., Zhang, M., \& Krajcik, J. (2005). A framework for supporting metacognitive aspects of online inquiry through software-based scaffolding. Educational Psychologist, 40(4), 235-244.

Robinson, K. (2009). The element: How finding your passion changes everything. New York: The Penguin Group.

Shepperd, J. A., Grace, J. L., \& Koch, E. J. (2008). Evaluating the electronic textbook: Is it time to dispense with the paper text? Teaching of Psychology, 35(1), 2-5.

Stuart, G. W., Tondora, J., \& Hoge, M. A. (2004). Evidence-based teaching practice: Implications for behavioral health. Administration and Policy in Mental Health and Mental Health Services Research, 32(2), 107-130.

Tabachnick, B. G. \& Fidell, L. S. (2007). Experimental designs using ANOVA. Belmont, CA: Thomson/Brooks/Cole.

Tatar, N., Akpinar, E., \& Feyzioglu, E. Y. (2013). The effect of computer-assisted learning integrated with metacognitive prompts on students' affective skills. Journal of Science Education and Technology, 22(5), 764-779. http://doi.org/10.1007/s10956-012-9429-1

Ustunluoglu, E. \& Gungor-Culha, D. (2012). Investigating Student Evaluation of Teachers by Using Latent Class Analysis: A Case Study at a Tertiary Level. International Journal of Education, 4(3), 147-159. 


\section{Supplementary Material 1: Sample questions to competency}

\section{Points question:}

CQ: Psychology is defined as the:

A. intuition-based approach to study human behavior.

B. speculative method to find answers about human cognition.

C. study of mental disorders and their treatment.

D. scientific study of behavior and mental processes.

Properties

APA Goal Outcome: Knowledge base psychology, Bloom's Taxonomy: Knowledge, Difficulty: Easy, and Learning Outcome: What is the science of psychology?

\section{Point question}

CQ: Which of the following statements regarding inhibitory messages is TRUE?

A. Inhibitory messages always increase the likelihood that a receiving neuron will fire.

B. Inhibitory messages decrease the likelihood that a receiving neuron will fire.

C. The dendrites of a neuron cannot receive both excitatory and inhibitory messages simultaneously.

D. Inhibitory messages make it more likely that an action potential will travel down its axon.

APA Goal Outcome: Knowledge base psychology and communication, Bloom's Taxonomy: Comprehension, Difficulty: Medium, and Learning Outcome: How does the nervous system communicate electrical and chemical messages from one part to another?

\section{Point question}

CQ: At a conference on terrorism research, a panel of psychologists is discussing suicide bombers. Dr. O'Dwyer outlines the role of charismatic leaders in encouraging the actions of suicide bombers. Dr. O'Connor argues that sometimes, suicide bombing may be seen as a rational response to a particular system of beliefs. Finally, Dr. Guzel reviews the internal traits associated with suicide bombing. Which of the following alternatives BEST identifies the subfields in which each of these psychologists probably specializes?

A. Dr. E. O'Dwyer: personality psychology; Dr. E. O'Connor: cross-cultural psychology; Dr. M. A. Guzel: social psychology

B. Dr. E. O’Dwyer: social psychology; Dr. E. O'Connor: personality psychology; Dr. M. A. Guzel cross-cultural psychology

C. Dr. E. O'Dwyer: political psychology; Dr. E. O'Connor: cross-cultural psychology; Dr. M. A. Guzel: personality psychology

D. Dr. E. O'Dwyer: cross-cultural psychology; Dr. E. O’Connor: experimental psychology; Dr. M. A. Guzel: personality psychology

Properties

APA Goal Outcome: Scientific inquiry and critical thinking

Bloom's Taxonomy: Application, Difficulty: Medium, and Learning Outcome: How do psychologists establish cause-and-effect relationship in research studies?

Correspondence: Ahmet Coymak, WEISS Research Scholar, Department of Psychology, Barnard College, Columbia University, New York, United States 